\title{
OPEN Antibacterial activity and characteristics of silver nanoparticles biosynthesized from Carduus crispus
}

\author{
Enerelt Urnukhsaikhan ${ }^{\bowtie}$, Bum-Erdene Bold, Aminaa Gunbileg, Nominchimeg Sukhbaatar \& \\ Tsogbadrakh Mishig-Ochir ${ }^{\bigotimes}$
}

In recent years' synthesis of metal nanoparticle using plants has been extensively studied and recognized as a non-toxic and efficient method applicable in biomedical field. The aim of this study is to investigate the role of different parts of medical plant Carduus crispus on synthesizing silver nanoparticles and characterize the produced nanoparticle. Our study showed that silver nanoparticles (AgNP) synthesized via whole plant extract exhibited a blue shift in absorption spectra with increased optical density, which correlates to a high yield and small size. Also, the results of zeta potential, $X$-ray diffraction, photon cross-correlation spectroscopy analysis showed the surface charge of - 54.29 \pm 4.96 mV (AgNP-S), - 42.64 +3.762 mV (AgNP-F), - 46.02 4 4.17 mV (AgNP-W), the crystallite size of $36 \mathrm{~nm}$ (AgNP-S), $13 \mathrm{~nm}$ (AgNP-F), $14 \mathrm{~nm}$ (AgNP-W) with face-centered cubic structure and average grain sizes of $145.1 \mathrm{~nm}, 22.5 \mathrm{~nm}$ and $99.6 \mathrm{~nm}$. Another important characteristic, such as elemental composition and constituent capping agent has been determined by energy-dispersive $X$-ray spectroscopy and Fourier transform infrared. The silver nanoparticles were composed of $\sim 80 \%$ $\mathrm{Ag}, \sim 15 \% \mathrm{~K}$, and $\sim 7.5 \% \mathrm{Ca}$ (or $\sim 2.8 \% \mathrm{P}$ ) elements. Moreover, the results of the FTIR measurement suggested that the distinct functional groups present in both AgNP-S and AgNP-F were found in AgNP-W. The atomic force microscopy analysis revealed that AgNP-S, AgNP-F and AgNP-W had sizes of $131 \mathrm{~nm}, 33 \mathrm{~nm}$ and $70 \mathrm{~nm}$ respectively. In addition, the biosynthesized silver nanoparticles were evaluated for their cytotoxicity and antibacterial activity. At $17 \mu \mathrm{g} / \mathrm{ml}$ concentration, AgNP-S, AgNP-F and AgNP-W showed very low toxicity on HepG2 cell line but also high antibacterial activity. The silver nanoparticles showed antibacterial activity on both gram-negative bacterium Escherichia coli $(5.5 \pm 0.2 \mathrm{~mm}$ to $6.5 \pm 0.3 \mathrm{~mm})$ and gram-positive bacterium Micrococcus luteus $(7 \pm 0.4 \mathrm{~mm}$ to $7.7 \pm 0.5 \mathrm{~mm}$ ). Our study is meaningful as a first observation indicating the possibility of using special plant organs to control the characteristics of nanoparticles.

Nanotechnology is a science that deals with the manipulation and fabrication of nanoparticles ${ }^{1}$. At least one or two dimensions of nanoparticles are within the range of $100 \mathrm{~nm}$ or less ${ }^{2}$. The nanometer-scaled particles have a unique property that differs them from their counterpart bulk material ${ }^{3}$, their small size offers a large surfaceto-volume ratio which causes a substantial biochemical and catalytic activity compared to the particles with the same composition ${ }^{1,4}$. Nanoparticles are employed in the areas of drug delivery, biomedical sciences, gene delivery, chemical industries, optics, mechanics, catalysis and etc. ${ }^{5}$. Among metal nanoparticles, silver nanoparticles (AgNP) garner much attention due to their strong antibacterial and anti-inflammation effect. AgNPs are utilized in various physical, biological and pharmaceutical fields, for instance, cream or ointment containing AgNPs are applied for burn and wounds to inhibit bacterial infection ${ }^{6}$. Although AgNP is integrated into many areas, the exact mechanism explaining the particle formation is not fully uncovered yet. The traditional method for the synthesis of AgNP is to use physical and chemical approach to produce nanoparticles with controlled and well-defined size and shapes ${ }^{7}$. However, the use of toxic substances, high pressure and energy such as laser ablation, hydrothermal synthesis, solvothermal synthesis, pyrolysis and inert gas condensation brought a demand for more biologically compatiblenanoparticles ${ }^{8,9}$. Recently, the synthesis of AgNP through biological method has been studied intensely. The biological method offers nanoparticles with high yield and stability compared 


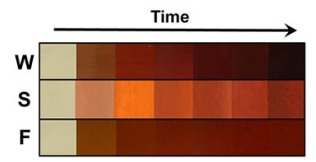

Figure 1. Color changes in biosynthesized silver nanoparticle with different parts of Carduus crispus. S-stem, F-flower and $\mathrm{W}$-whole plant.

to the conventional physical and chemical approach ${ }^{10}$. AgNP can be biosynthesized by bacteria, fungi, yeast, actinomycetes and plant, thus avoiding the use of toxic substances and enabling for further application in medical and pharmaceutical field ${ }^{11}$. The application of plants for the synthesis of AgNP has gained significant attention. Plant-mediated synthesis of AgNP has many advantages, it can be obtained under ambient temperature with low cost and the process is relatively fast compared to bacteria, where a long process of maintaining cell culture is required $^{12}$. Plants contain a wide range of metabolites that can aid in reducing silver ion, stabilizing and capping $\mathrm{AgNP}^{13}$, therefore the concentration and composition of AgNP will vary depending on the plant type $\mathrm{e}^{3}$. This is especially the case for the medicinal plant as it is a rich source of complex phytochemicals and antioxidants. The main antioxidants of medicinal plants are polyphenols, carotenoids, and vitamins. The medicinal plants display a wide range of anti-inflammatory, antibacterial, antiviral, anti-aging, and anti-cancer activities ${ }^{14}$. In addition to polyphenols found in plants, there are other biomolecules responsible for reducing and capping $\mathrm{AgNP}^{15}$, these include polysaccharides, aldehydes, ketones, proteins, enzymes, amino acids, and caffeine ${ }^{16}$. The complex biomolecules found in medicinal plant assist in the reduction of metal ions and stabilization of nanoparticles into desired shape and size ${ }^{17}$. The plant-mediated synthesis of AgNP is relatively simple as it requires only plant extract and silver salt, thereafter it undergoes a reduction process ${ }^{18}$. There are many reports published regarding a medicinal plant-mediated synthesis of AgNP, these include Gmelina aroberea ${ }^{19}$, Tecomella undulata ${ }^{20}$, Artemisia absinthium ${ }^{21}$, Datura stramonium ${ }^{22}$, Calliandra haematocephala ${ }^{23}$, Carica papaya ${ }^{24}$ etc. Carduus crispus is a plant species of the family Asteraceae that can be found in Mongolia. The medicinal effect ranges from a stomachache, rheumatism, atherosclerosis to cancer. And due to its medical properties, it is broadly applied in Mongolian traditional medicine ${ }^{25}$. The main activity of Carduus crispus is coagulation, antioxidant and anticonvulsive activity ${ }^{26}$. According to the study done by Baumberger the major compounds detected in Carduus crispus are flavonoids and coumarins, also alkaloids saccharides, essential oil, rubber, lipids contained in small quantities ${ }^{27}$. There are no available reports on the synthesis of AgNP using Carduus crispus as the plant extract. The mechanism of action of AgNP is not yet completely understood, however there are several hypotheses available explaining the antibacterial, anti-inflammatory and anti-cancer activity. It is known that nanoparticles have a large surface area that either penetrates the cell or attaches itself to the cell wall ${ }^{11}$, causing a disturbance in the membrane permeability making it porous ${ }^{28}$, and this action leads to a further leakage of cell content. Moreover, the appearance of pores on membrane result to diffusion of nanoparticles into the cell where it binds with sulfur and phosphorus-containing proteins, thus leading to the inactivation of proteins and DNA ${ }^{17}$. Another hypothesis suggests that the antibacterial activity of AgNPs results from the release of $\mathrm{Ag}^{+}$ions through the oxidation dissolution process. Silver ions oxidized from AgNP mainly interact with thiol groups of various enzymes and protein, thereby interfering with the respiratory chain and disrupting the bacterial cell wall. Silver ions also facilitate the generation of reactive oxygen species (ROS), which is considered as the main cause for most cell death through the inactivation of DNA replication and ATP production ${ }^{29}$. The present study aimed to synthesize silver nanoparticles with medicinal plant Carduus crispus extracts and characterize the final product, and evaluate their antibacterial activities.

\section{Results and discussion}

UV-Vis spectra analysis and color change. The visual color change from pale yellow to dark brown in response to time can be seen as evidence of silver ion reduction to AgNP. The change in color of biosynthesized AgNP is due to the excitation of surface plasmon resonance (SPR). Several studies done on the synthesis of AgNP via medicinal plant suggest the absorption peak around 412-470 $\mathrm{nm}$ with the duration of synthesis from $4 \mathrm{~h}$ till $24 \mathrm{~h}$, these include medicinal plants, such as Abutilon indicum, Aegle marmelos, Azadirachta indica, Calliandra haematocephala, Calotropis procera, Carica papaya, Helicteres isora, Lawsonia inermi, Leptadenia reticulate, Rheum palmatum, Tecomella undulata, Tagetes erecta, Urtica dioica. The rate of color change from light yellow to dark brown varied in these studies, the earliest color change began within $1 \mathrm{~h} \mathrm{till} 4 \mathrm{~h}^{4,20,23,24,30-38}$. Alternatively, different studies utilizing non-medicinal plants for the AgNP synthesis, such as Allium cepa, Chenopodiastrum murale, Cyperus rotundus, Eleusin indica, Euphorbia hirta, Melastoma malabathricum, Musa acuminate, Pachyrhizus erosus, Rubus glaucus exhibited absorption peak from 401-780 nm and was synthesized for $72 \mathrm{~h}$ till 14 days. The color change of AgNP synthesized via C. murale turned to brown color after incubating overnight ${ }^{39-43}$. The difference in color change rate might be due to the different properties of the plant, specifically, the medicinal plant contains a wide range of phytochemicals, such as flavonoids, polyphenols, terpenoids, etc. $^{44}$ that assist in the formation of silver nanoparticles. Iravani et al. ${ }^{5}$ reported in their studies that flavonoids, polyphenols, terpenoids, alkaloids and proteins are the main constituents responsible for the reduction and stabilization of silver nanoparticles. Figure 1 shows the result of color change of the synthesized silver nanoparticle with different organs of Carduus crispus, such as stem, flower and the whole plant. It can be seen that different plant organs affected differently on silver nanoparticle synthesis, and particularly whole plant extract facilitated better silver nanoparticle formation compared to the stem and flower extract. The synthesis of silver nanoparti- 

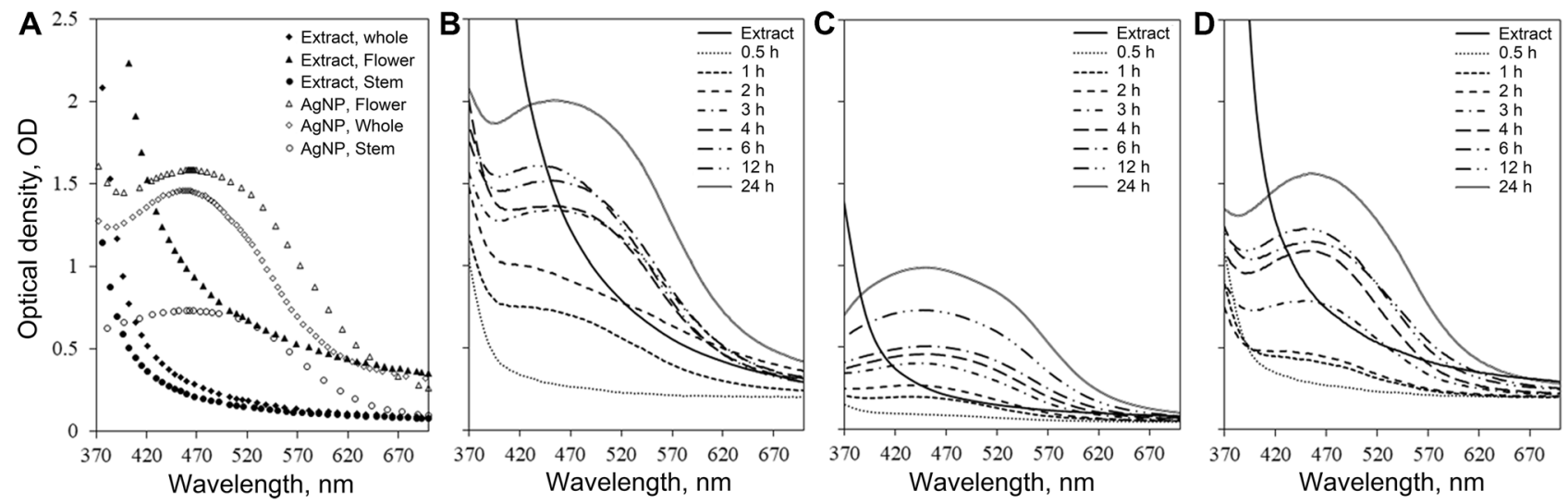

Figure 2. UV-Vis spectra for the reaction mixture containing of silver nanoparticles synthesized from Carduus crispus flower (AgNP-F), stem (AgNP-S) and whole plant (AgNP-W). Shown are the UV-Vis absorption spectra from 370 to $700 \mathrm{~nm}$ of all plant organs and synthesized (A) AgNPs, (B) AgNP-W, (C) AgNP-S, and (D) AgNP-F.

\begin{tabular}{|l|l|l|}
\hline & Average zeta potential & Average mobility \\
\hline AgNP-W & $-46.02 \pm 4.17$ & $-3.52 \pm 0.31$ \\
\hline AgNP-S & $-54.29 \pm 4.96$ & $-4.19 \pm 0.38$ \\
\hline AgNP-F & $-42.64 \pm 3.762$ & $-3.25 \pm 0.28$ \\
\hline
\end{tabular}

Table 1. Average zeta potential and mobility of AgNP-W, AgNP-S and AgNP-F.

cles with whole plant extract exhibited a darker color change. The variation in color change might be due to the different phytochemical content in the plant organs. Following the visual color change study, the formation and stability of silver nanoparticles synthesized with flower, stem, and whole plant of Carduus crispus were characterized using a UV-Vis spectrophotometer (Fig. 2). The results revealed that silver nanoparticles synthesized with whole plant (AgNP-W) exhibited higher absorption compared to silver nanoparticles synthesized using plant organs such as flower (AgNP-F) and stem (AgNP-S). The higher absorption is directly proportional to the higher yield of silver nanoparticles in colloidal solution ${ }^{45}$. Additionally, the size of the synthesized silver nanoparticle was studied by observing the shift of the absorption peak towards a longer or shorter wavelength ${ }^{8,46}$. In Fig. 2 b-d, silver nanoparticles were measured at various times, and according to our results, the AgNP-W exhibited blueshift in contrast to AgNP-F and AgNP-S, which can be interpreted as the formation of smaller-sized silver nanoparticles.

Zeta potential analysis. Zeta potential explains the stability, dispersion and surface charge of the nanoparticles. The zeta potential greater than $+30 \mathrm{mV}$ or less than $-30 \mathrm{mV}$ indicates high stability of nanoparticles in dry powder form ${ }^{31}$. The high negative value produces repulsion between similarly charged particles in suspension, therefore resisting aggregation ${ }^{47}$. Several studies were done on silver nanoparticle synthesis with a medicinal plant such as Potentilla fulgens, Alpinia calcarata, Pestalotiopsis micospora, Urtica dioica, Jatropha curcas which resulted inzeta potential of $-18 \mathrm{mV},-19.4 \mathrm{mV},-35.7 \mathrm{mV},-24.1 \mathrm{mV}$, and $-23.4 \mathrm{mV}$ respectively $\mathrm{y}^{4,6,12,47,48}$. Our results showed that zeta potential of the synthesized AgNP-W, AgNP-S, AgNP-F had an average zeta potential of $-46.02 \pm 4.17($ AgNP-W),$-54.29 \pm 4.96($ AgNP-S) and $-42.64 \pm 3.762$ (AgNP-F) (Table 1). The zeta potential of AgNP-S exhibited a higher average value compared to the AgNP-W and AgNP-F, this may be due to the presence of different phytochemicals in each sample that reduces and cap silver nanoparticles. The results of the zeta potential analysis suggest that silver nanoparticles synthesized with Carduus crispus exhibit high stability and resist agglomeration. Figure 3 showed that zeta potential values of AgNP-W, AgNP-S, and AgNP-F fall within the normal distribution curve, which indicates that synthesized silver nanoparticles are fairly monodisperse.

FTIR spectral analysis of synthesized AgNP by Carduus crispus. The presence of the functional groups capping AgNP synthesized using Carduus crispus is analyzed by FTIR and shown in Fig. 4. The presence of various organic compounds in the plant reveals multiple peaks compared to the chemical method where only a few and strong peaks are displayed ${ }^{49,50}$. The results of our FTIR analysis showed the presence of several functional groups in AgNP-W, AgNP-S, AgNP-F. Additionally, the functional groups in AgNP-F and AgNP-S were present in AgNP-W samples as well, this may be attributed to the various phytochemicals capping the silver nanoparticles that are found both in flower and stem of Carduus crispus. The strong characteristic bands at $\sim 3418 \mathrm{~cm}^{-1}$ to $3429 \mathrm{~cm}^{-1}$ and $2361 \mathrm{~cm}^{-1}$ in all samples AgNP-S, AgNP-F, AgNP-W are assigned to the O-H stretching/N-H stretching of amides and $2361 \mathrm{~cm}^{-1}$ to the $\mathrm{C} \equiv \mathrm{C}$ stretching. Additionally, the weak band at $\sim 1017$ $\mathrm{cm}^{-1}$ to $1022 \mathrm{~cm}^{-1}$ and $\sim 828 \mathrm{~cm}^{-1}$ assigned to carbohydrates and $-\mathrm{C}=\mathrm{O}$ bending were found in all samples AgNP-S, AgNP-F, and AgNP-W. C-O stretching is present in AgNP-F which was observed from the very strong 

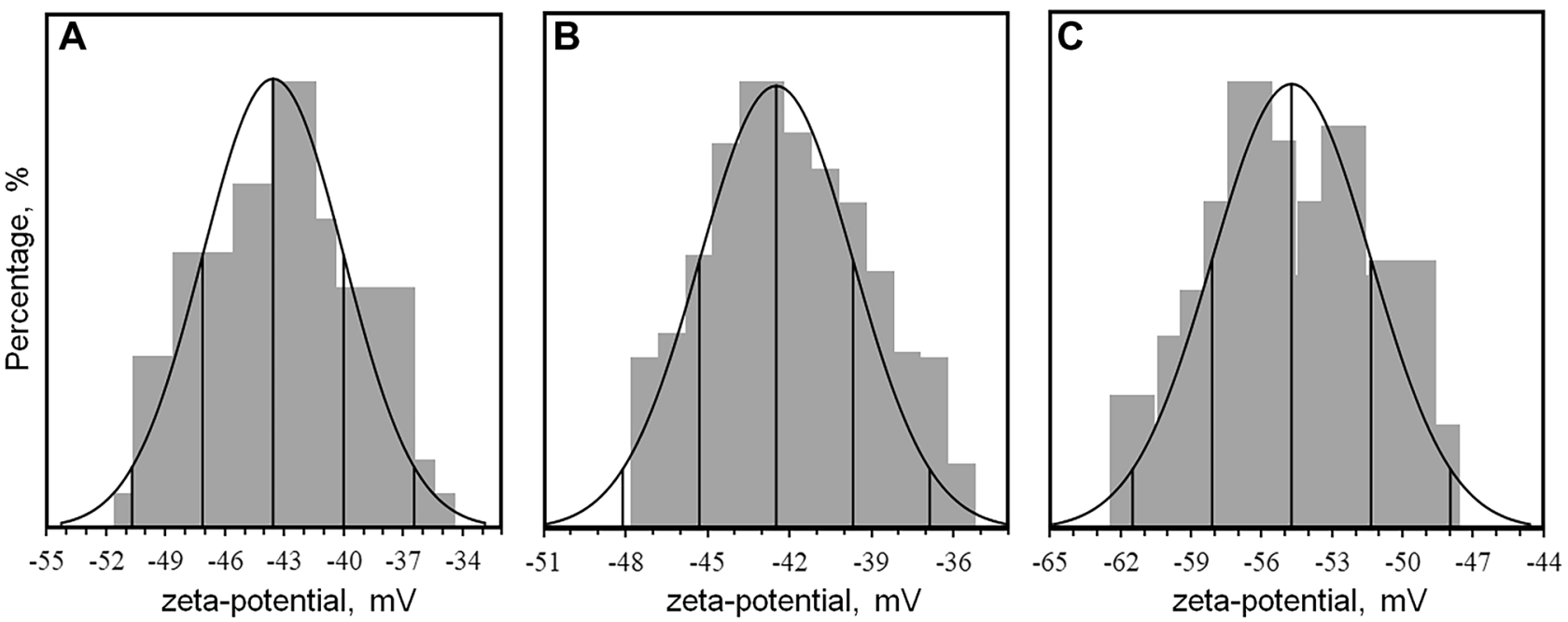

Figure 3. Zeta potential analysis of (A) AgNP-W, (B) AgNP-F and (C) AgNP-S.

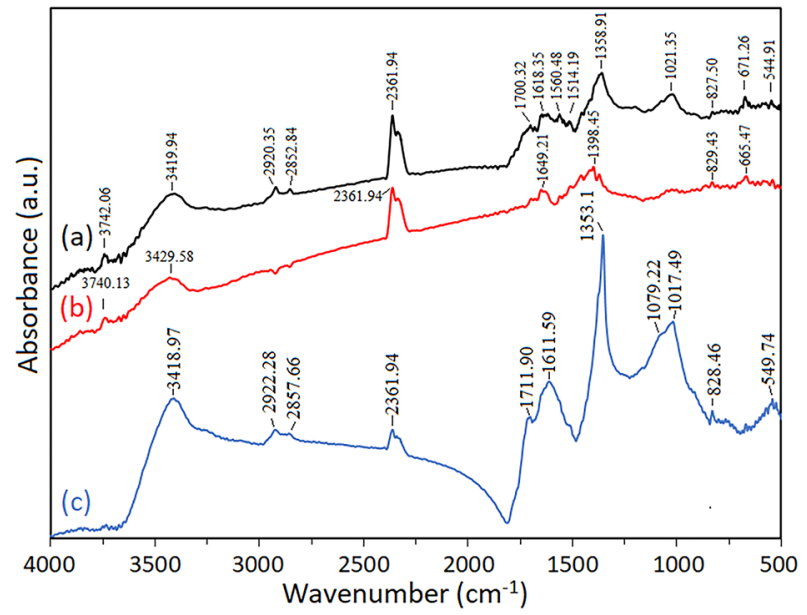

Figure 4. Fourier transform infrared spectra of (a) AgNP-W, (b) AgNP-S, and (c) AgNP-F.

band at $1353 \mathrm{~cm}^{-1}$. The weak bands at $2922 \mathrm{~cm}^{-1}$ and $2857 \mathrm{~cm}^{-1}$ of $\mathrm{CH}_{3}$ stretch of alkane/carboxylic acids present in AgNP-F and were absent in AgNP-S. The band detected at $3418 \mathrm{~cm}^{-1}$ to $3429 \mathrm{~cm}^{-1}$ and $1618.35 \mathrm{~cm}^{-1} \mathrm{cor}_{-}$ respond to the presence of phenolic compounds and flavonoids, and the band found on $1021.35 \mathrm{~cm}^{-1}$ indicates carboxylic acid, ester, and ether groups of proteins and metabolites that may be involved in the synthesis of nanoparticles ${ }^{33}$. Our result show that the strong band detected at $1611 \mathrm{~cm}^{-1}$ and $1017 \mathrm{~cm}^{-1}$ from AgNP-F correspond to the presence of flavonoids and proteins. On the other hand, weak bands detected at $\sim 1696 \mathrm{~cm}^{-1}$ to $1371 \mathrm{~cm}^{-1}$ correspond to alcohol, carboxylic acids, alkyl halides/carboxylic acids/ester, alkenes/alkyl halides/ aromatics, alkynes/alkyl halides stretch that peaks found from AgNP-S. According to Baumberger ${ }^{27}$ the major compounds detected in Carduus crispus are flavonoids and coumarins, in addition, alkaloids, saccharides, essential oil, rubber and lipids contained in small quantities which is in line with the presence of flavonoids and phenolic compounds in our synthesized AgNP. The AgNP-F and AgNP-S contained different functional groups that correspond to various compounds, and AgNP-F revealed that it has a strong correlation with flavonoids from Carduus crispus. The results of FTIR and UV-Vis spectra analysis confirm that these functional groups are the capping and reducing agents responsible for the synthesis of AgNPs.

XRD, PCCS, SEM/EDX and AFM analysis. The crystalline nature of the synthesized AgNP was confirmed by X-ray crystallography. The XRD pattern of the nanoparticles was analyzed with an XRD instrument and shown in Fig. 5. Bragg reflection of the $2 \theta$ peaks was observed at $32.25^{\circ}$ to $81.62^{\circ}$ and corresponded to (111), (200), (220), (311), (222) plane lattice which can be indexed to the face-centered cubic crystal nature of the silver. The average crystallite size was calculated using the Scherrer equation. The average crystallite sizes were $13 \mathrm{~nm}$ (AgNP-F), $14 \mathrm{~nm}$ (AgNP-W) and $36 \mathrm{~nm}$ (AgNP-S). The results of our study are in line with other published literature, the crystal nature of silver nanoparticles synthesized with Tagetes erecta ${ }^{31}$, Urtica dioica ${ }^{4}$, Aegle marmelos was face-centered cubic with diffraction peaks of (111), (200), (220), (311) respectively ${ }^{34}$. PCCS 


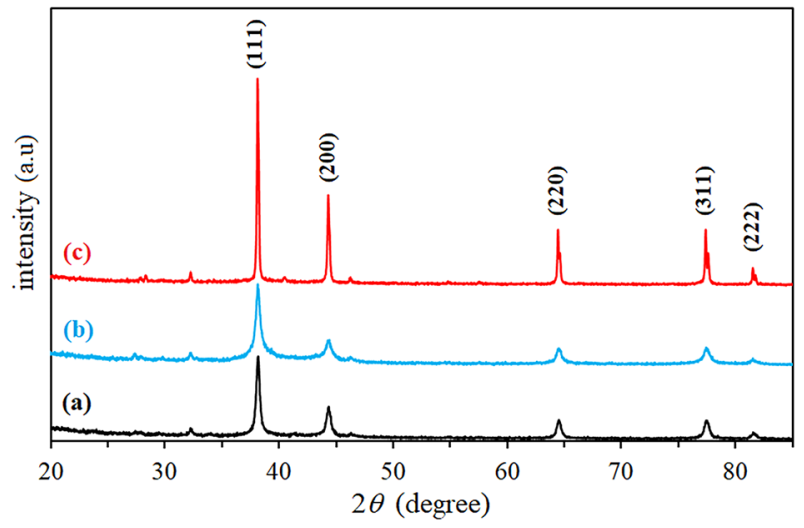

Figure 5. XRD spectra of (a) AgNP-W, (b) AgNP-F, (c) AgNP-S. Peaks are appeared at 111, 200, 220, 311 and 222.
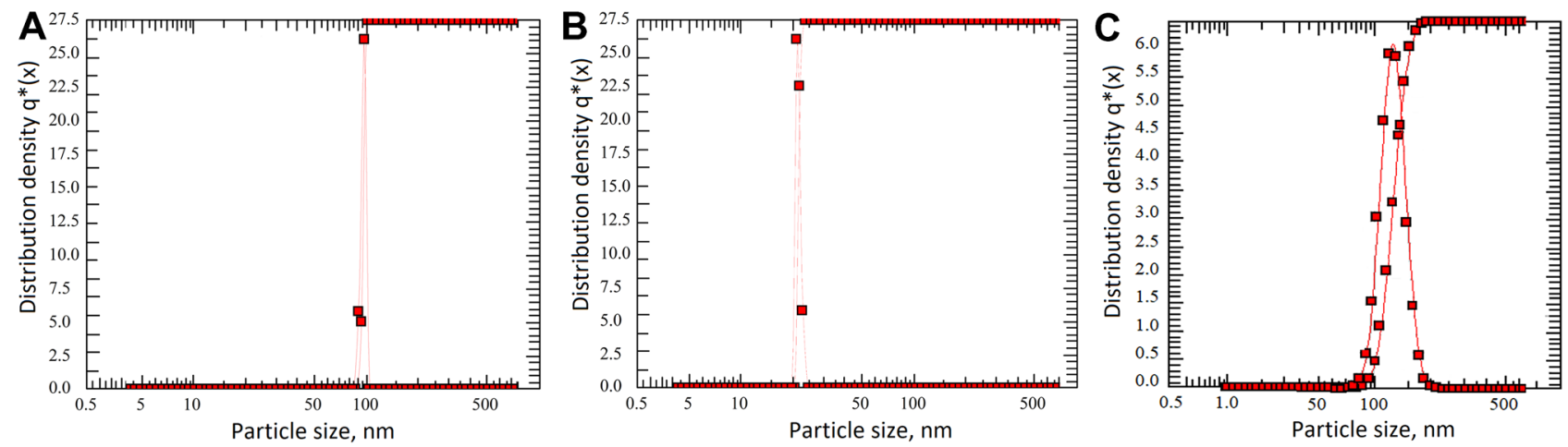

Figure 6. PCCS analysis: particle number distribution of synthesized AgNP-W (A), AgNP-F (B) and AgNP-S (C).

\begin{tabular}{|l|l|l|l|l|l|}
\hline & Silver, \% & Potassium, \% & Calcium, \% & Phosphorus, \% & Chlorine, \% \\
\hline AgNP-W & $77 \pm 1$ & $15.1 \pm 0.5$ & $2.8 \pm 0.1$ & $1.2 \pm 0.1$ & $3.9 \pm 0.21$ \\
\hline AgNP-F & $82 \pm 1$ & $15.2 \pm 0.4$ & - & $2.8 \pm 0.15$ & - \\
\hline AgNP-S & $77 \pm 1$ & $15.5 \pm 0.5$ & $7.5 \pm 0.2$ & - & - \\
\hline
\end{tabular}

Table 2. Elemental composition of the synthesized silver nanoparticles by Carduus cripus.

is a technique based on the Brownian motion that measures the average nanoparticle size (grain size). In Fig. 6, the average particle size of AgNP-W, AgNP-F and AgNP-S was $99.6 \mathrm{~nm}, 22.5 \mathrm{~nm}$ and $145.1 \mathrm{~nm}$ respectively. The difference between PCCS and XRD analysis lies in the measurement method of the particle. Application of the Scherrer equation on XRD data gives the average crystallite size, specifically the size of a single crystal inside the particle or grain. The morphological and elemental analysis was done on Scanning Electron Microscope (SEM) and Energy Dispersive X-Ray Spectroscopy (EDX). The elemental composition of the synthesized silver nanoparticle was assessed using EDX spectroscopy (Table 2). The results in Fig. 7 showed that AgNP-W, AgNP-S, and AgNP-F contained silver and potassium elements together with several other elements that differed in AgNP-F and AgNP-S samples, i.e. AgNP-F included phosphorus 2.8\%, potassium 15.2\%, and AgNP-S had calcium 7.5\%, pottassium 15.5\% elements. In contrast, AgNP-W contained all the elements including the elements that differed in AgNP-F and AgNP-S. Interestingly, the silver element in AgNP-F had the highest content of 82\% compared to AgNP-W and AgNP-S which had a silver content of $79 \%$ and $77 \%$ respectively. Another observation on EDX analysis revealed that AgNP-W, AgNP-F, AgNP-S did not show the presence of nitrogen peak, this indicates that trace ions from $\mathrm{AgNO}_{3}$ are absent in the samples. The size of biosynthesized AgNP-W, AgNP-F and AgNP-S was determined with Atomic Force Microscopy (AFM). Figure 8 show that the size of nanoparticles differed, for instance, AgNP-W had a size of $70 \mathrm{~nm}, \mathrm{AgNP}-\mathrm{F}$ with size $33 \mathrm{~nm}$ and AgNP-S with size $131 \mathrm{~nm}$. Figure 8 (A-C, E-G and I-K) represents the two dimensional images of AgNP-W, AgNP-F and AgNP-S. Figure 8 (D, H and L) shows the three dimensional image of AgNP-W, AgNP-F and AgNP-S respectively. The different composition 

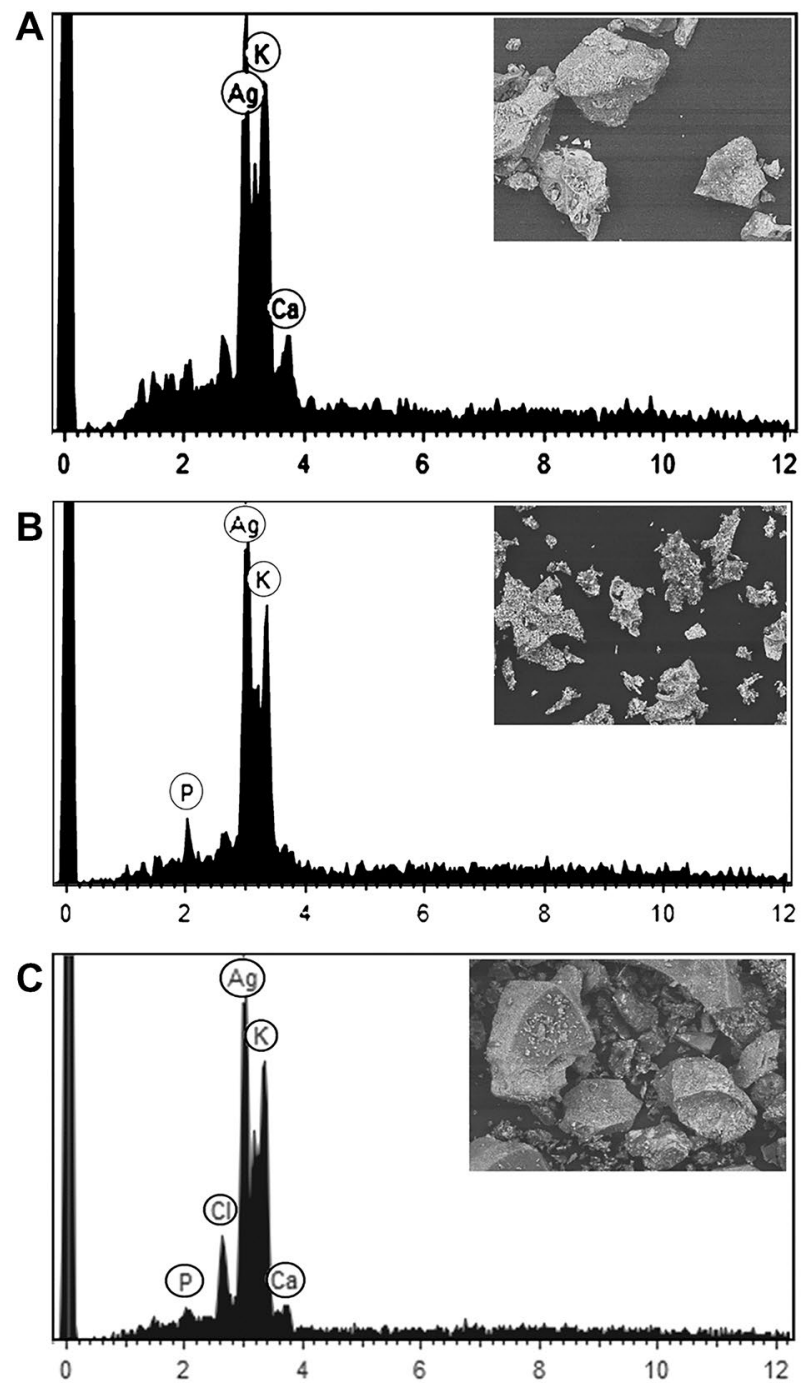

Figure 7. EDX spectra for (A) AgNP-F, (B) AgNP-S and (C) AgNP-W along with SEM image area (inset).

of plant organs, such as stem, flower and whole plant could be the reason for the observed variability in, color change, UV-Vis absorption, EDX, FTIR. In addition, the results of AFM data and XRD show that the synthesis of AgNP can be manipulated with different plant organs.

Antibacterial activity. The antibacterial activity of silver nanoparticles was studied against pathogenic bacterial strains of gram-negative E.coli and gram-positive M.luteus using the well diffusion method (Fig. 9). Standard antibiotics such as Penicillin G and Chloramphenicol, plant extracts, $\mathrm{AgNO}_{3}$ and distilled water were chosen as the control group. The results of the antibacterial activity showed that all synthesized silver nanoparticles had efficient antibacterial activity against both gram-negative E.coli and gram-positive M.luteus bacterial strains. The inhibition zone of AgNP-F, AgNP-W and AgNP-S against E.coli and M.luteus were 6.5 $\pm 0.3,6 \pm 0.2$, $5.5 \pm 0.2$ and $7.5 \pm 0.3,7 \pm 0.2,7.7 \pm 0.4 \mathrm{~mm}$ respectively. The plant extract and $\mathrm{AgNO}_{3}$ did not reveal any antibacterial activity against both E.coli and M.luteus, which can be interpreted that AgNP-W, AgNP-F, and AgNP-S are solely responsible for the antibacterial activity. The mode of action of AgNPs against bacteria is not completely understood yet. However, several hypotheses are explaining the antibacterial activity of silver nanoparticle: (1) generation of reactive oxygen species; (2) release of $\mathrm{Ag}+$ ions from AgNPs denaturize proteins by bonding with sulfhydryl groups; (3) attachment of AgNPs on bacteria and subsequent damage to bacteria ${ }^{4,11,24}$. The multiple published reports on the antibacterial activity of silver nanoparticles against gram-negative and gram-positive bacteria showed that silver nanoparticles had a slight antibacterial activity on gram-positive bacteria ${ }^{6,22,31,36}$. Interestingly, AgNP synthesized by Carduus crispus exhibited effective inhibition on both gram-positive and gram-negative bacteria which can be interpreted that the antibacterial activity of silver nanoparticles (AgNP-W, AgNP-F and AgNP-S) is not affected by the difference in the bacterial wall. 

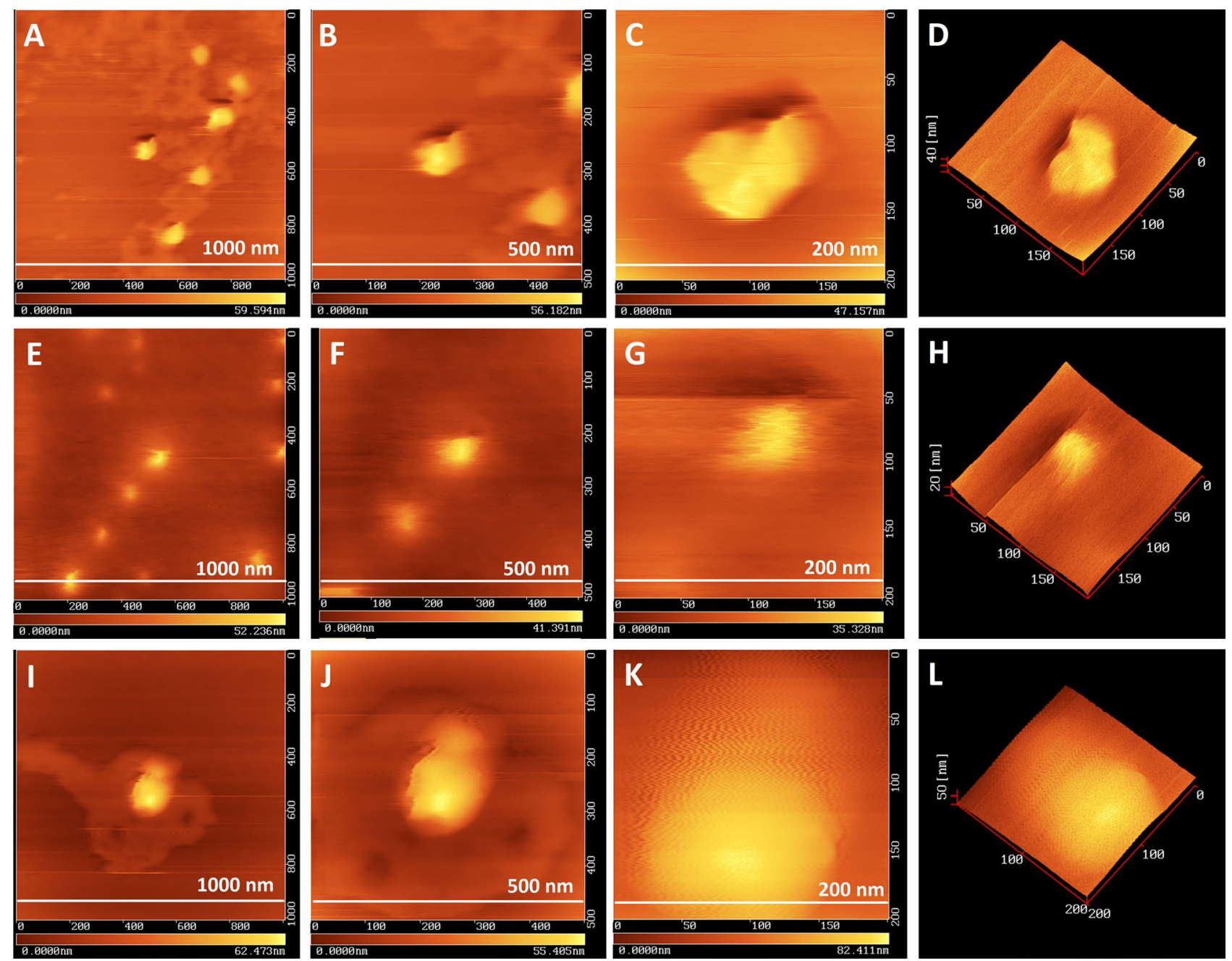

Figure 8. Atomic force microscopy images (2D and 3D) of silver nanoparticles on siliconized cover slide; AgNP-W (A-D), AgNP-F (E-H) and AgNP-S (I-L).

In-vitro cytotoxicity assay. Cytotoxicity is considered as an important indicator for cell viability, therefore in this study we employed crystal violet assay to investigate the effect of different concentration of AgNP-W, AgNP-F and AgNP-S on the adherent human hepatoma cell line HepG2 (Fig. 10). The liver is an important organ with detoxifying effect, additionally, it is considered as an accumulation site for $\mathrm{AgNPs}^{51}$. In this study, the untreated HepG2 cell lines revealed significant adherence to the well plate. On the other hand, the treated cells with nanoparticles exhibited small decrease in cell viability after $24 \mathrm{~h}$ incubation at 3 to $17 \mu \mathrm{g} / \mathrm{ml}$. The cell viability of these treated groups with AgNP-W, AgNP-F and AgNP-S were $87.93 \pm 4.87 \%, 92.24 \pm 1.21 \%$ and $86.20 \pm 2.43 \%$ at $17 \mu \mathrm{g} / \mathrm{ml}$. The toxicity of AgNPs to bacteria and human cells is widely known, however, the result of our study suggests that AgNPs synthesized by medicinal plant Carduus crispus with concentration of 3 to $17 \mu \mathrm{g} / \mathrm{ml}$ have low toxicity on HepG2 cell line (Fig. 10A,B). In addition, biosynthesized silver nanoparticles possessed efficient antibacterial activity against Gram-negative and Gram-positive bacteria (Fig. 9). The antibacterial activity of the synthesized AgNPs and their low toxicity to human cells may enable further application in biomedical field. The low toxicity of biosynthesized AgNPs to adherent human cells are similar to other published reports ${ }^{52}$.

\section{Conclusion}

The synthesis of silver nanoparticles via biological method, specifically plant extracts provides a natural, ecofriendly, cost-effective, rapid synthesis of silver nanoparticles. The present study reports the synthesis of silver nanoparticles with medicinal plant Carduus crispus in reducing silver ions and stabilizing the silver nanoparticles. It has been reported that medicinal plants are a rich source of phenolic compounds such as flavonoids and phenolic acids, etc. Additionally, plant organs contain different contents of phenolic compounds, therefore flower, stem, and whole plant of Carduus crispus were chosen for this study. Afterwards, the synthesized silver nanoparticles were characterized using visual color change, UV-Vis spectroscopy, zeta potential, FTIR, XRD, PCCS, SEM-EDX and AFM. The characterization of AgNP-W, AgNP-F, and AgNP-S revealed that AgNP-W had a higher yield, synthesis rate, and smaller-sized silver nanoparticles. The zeta potential conveys the stability and the result of all the synthesized silver nanoparticles showed the zeta potential value of $-46.02 \pm 4.17$ (AgNP-W), 

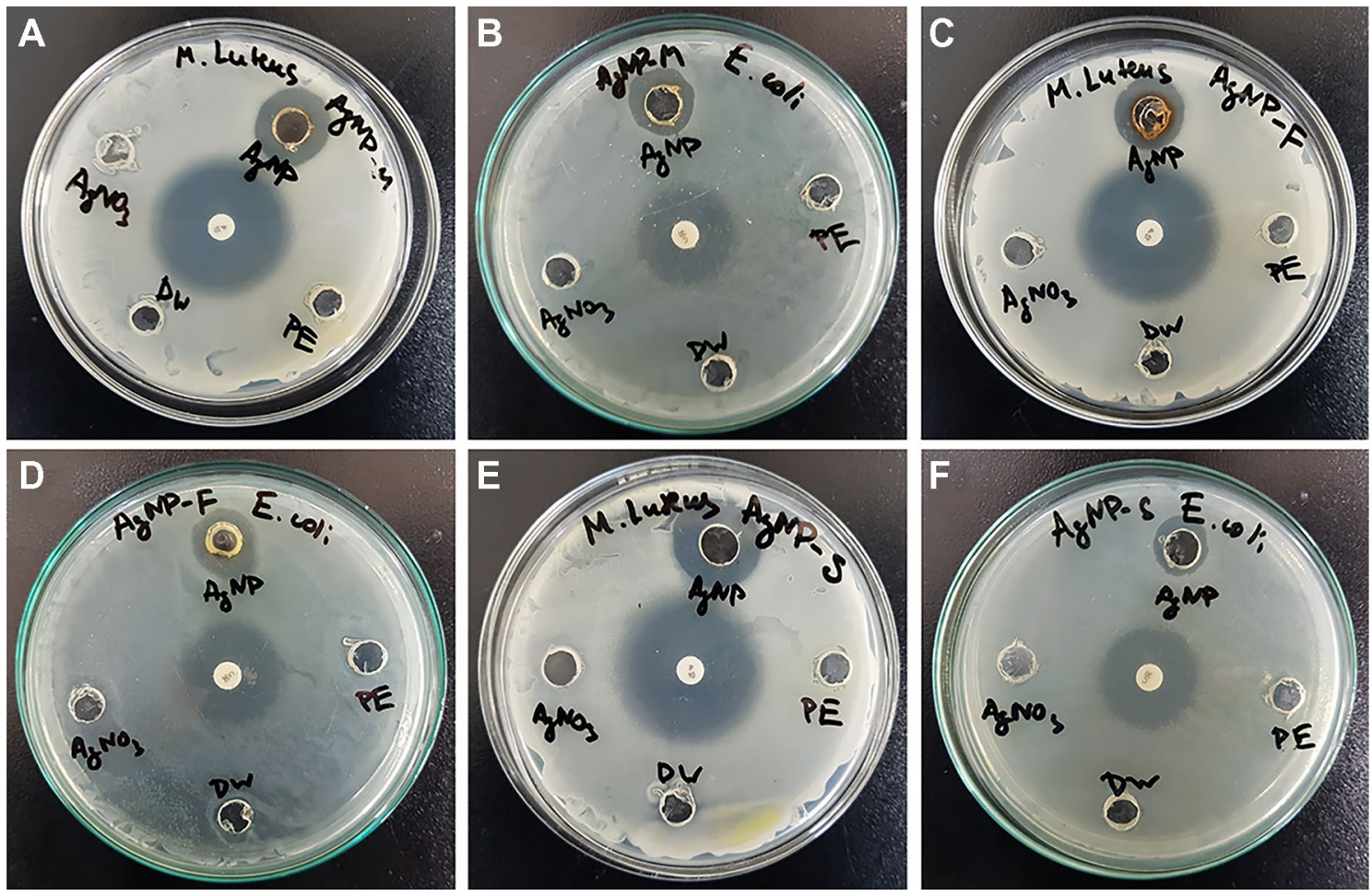

Figure 9. Petri dishes showing the zone of inhibition of synthesized AgNP-W on (A) M. luteus and (B) E. coli, and AgNP-F on (C) M. luteus and (D) E. coli, AgNP-S on (E) M. luteus and (F) E. coli (AgNP: silver nanoparticle, $\mathrm{AgNO}_{3}$ : silver nitrate, DW: distilled water, $\mathrm{PE}$ : plant extract).
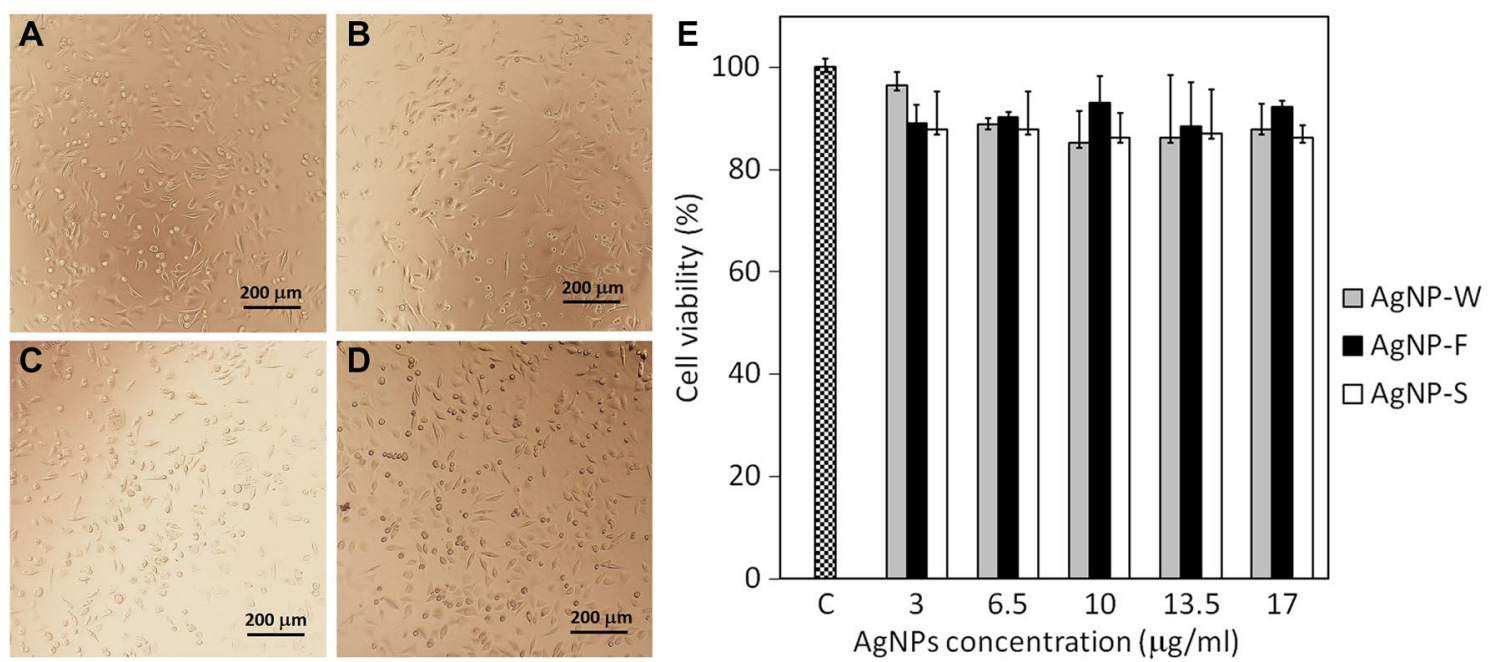

Figure 10. A microscopic pictures of HepG2 cells treated with AgNPs for $24 \mathrm{~h}$ in cell culture: control (A), AgNP-W (B), AgNP-F (C) and AgNP-S (D). After 24 h, the cell toxicity effect was examined with Crystal Violet (E).

$-54.29 \pm 4.96$ (AgNP-S), and $-42.64 \pm 3.762$ (AgNP-F) which indicates highly stable silver nanoparticles. The variation in zeta potential may be due to the different phytochemical properties of the plant. Then FTIR analysis was utilized to study the role of phytochemical properties in plants for the synthesis of silver nanoparticles, the results showed that different functional groups in AgNP-F and AgNP-S were also present in AgNP-W samples as well. And based on the UV-Vis spectra analysis, AgNP-W and AgNP-F had the highest absorbance compared to AgNP-S, therefore we can conclude that the functional groups present and coincided in both AgNP-F and AgNP-W may play a contributing role in capping and synthesis of silver nanoparticles, these include functional groups with bands at $2922.28 \mathrm{~cm}^{-1}, 2857.66 \mathrm{~cm}^{-1}, 1711.90 \mathrm{~cm}^{-1}, 1611.59 \mathrm{~cm}^{-1}, 1079.22 \mathrm{~cm}^{-1}$ and $1017.49 \mathrm{~cm}^{-1}$ which correspond to alkanes, carboxylic acids, ketones, alkenes, amides, esters/ethers/amides, alkyl halides. Furthermore, strong bands at $3418 \mathrm{~cm}^{-1}$ to $3429 \mathrm{~cm}^{-1}, 1618.35 \mathrm{~cm}^{-1}$ to $1611 \mathrm{~cm}^{-1}$, and $1017 \mathrm{~cm}^{-1}$ correlates to 
flavonoids and phenolic compounds. The EDX analysis detected the following elements, such as silver, potassium, phosphorus in AgNP-F; silver, potassium, calcium, chloride, and phosphorus in AgNP-W; finally, silver, potassium, calcium in AgNP-S samples. The synthesized silver nanoparticles had an average crystallite sizes of $14 \mathrm{~nm}$ (AgNP-W), $13 \mathrm{~nm}$ (AgNP-F) and $36 \mathrm{~nm}$ (AgNP-S) with face-centered crystal structure and average grain sizes of $99.6 \mathrm{~nm}$ (AgNP-W), $22.5 \mathrm{~nm}$ (AgNP-F) and 145.1 nm (AgNP-S). The sizes detected in AFM was $70 \mathrm{~nm}$ (AgNP-W), $33 \mathrm{~nm}$ (AgNP-F) and $131 \mathrm{~nm}$ (AgNP-S). Although the method of synthesis varied in AgNPF, AgNP-W, and AgNP-S, their antibacterial activity showed efficient inhibition on both gram-negative and gram-positive bacteria. Based on these results, we can conclude that silver nanoparticles synthesized by whole plant of Carduus crispus have a faster rate of synthesis, higher yield with a smaller size, and high antibacterial activity against both gram-negative and gram-positive bacteria. The overall results show that the effectiveness of the synthesis of the flower for AgNP appears similar to using whole plant. Additionally, we have shown that the process of synthesizing nanoparticles can be manipulated with specific organs of plant, for example, particle size and synthesis duration, biological effect, etc. Our study is meaningful as a first observation indicating the possibility of using special plant organs to control the characteristics of nanoparticles. Moreover, further studies are required in this area.

\section{Methods}

Chemicals and plant. The Carduus crispus was collected from Khuder soums, Selenge province of Mongolia (GPS coordinates: N 49.641772, E 107.80935) and the taxonomy was determined by a botanist Kh.Khaliunaa from National University of Mongolia. The Carduus crispus used for the study does not violate the local regulations of Mongolia, the permission for the plant collection was granted from the Ministry of Environment and Tourism of Mongolia. The collected plant specimen of Carduus crispus was deposited into the publicly available herbarium of National University of Mongolia with deposition number UBU0002509. The Silver Nitrate $\left(\mathrm{AgNO}_{3}\right)$ with $\geq 99.0 \%$ purity was purchased from Sigma Aldrich. All the other relevant reagents are up to the standard.

Preparation of plant extract. The whole plant was washed with tap water in order to remove the adhering dust and soil particles, followed by washing with distilled water. $100 \mathrm{ml}$ of distilled water was added to $5 \mathrm{~g}$ of Carduus crispus and boiled for $15 \mathrm{~min}$, then cooled at ambient temperature. Afterward, it was filtered by Whatman filter paper and centrifuged twice at $10,000 \mathrm{rpm}$ to obtain a plant extract. Finally, the extract was ready for the synthesis of AgNP.

Synthesis of silver nanoparticle. The aqueous plant extract of Carduus crispus and $\mathrm{AgNO}_{3}(1 \mathrm{mM})$ were mixed with the ratio of $1: 16$, then the solution was exposed to the daylight and the reaction took place at the various time at room temperature. In order to obtain silver nanoparticles in powdered form, the solution was vaporized on a vacuum evaporator, and the final product of AgNP was kept inside the oven at a temperature of $300^{\circ} \mathrm{C}$ for $4 \mathrm{~h}$.

Characterization of AgNP synthesized by Carduus crispus. AgNP was successfully synthesized by using Carduus crispus. A color change from pale yellow to colloidal dark brown indicated the formation of silver nanoparticles. UV-Vis spectra analysis offers an insight into the synthesis and stability of the AgNP. Formation of the biosynthesized AgNP was determined by the UV-Vis spectrophotometer (Shimadzu UV-2500PC Series) at $30 \mathrm{~min}, 1 \mathrm{~h}, 2 \mathrm{~h}, 3 \mathrm{~h}, 4 \mathrm{~h}, 6 \mathrm{~h}, 12 \mathrm{~h}, 24 \mathrm{~h}$ and was carried out at 350-700 nm range. FTIR spectrum was recorded in the range of 500 to $4000 \mathrm{~cm}^{-1}$ through the potassium bromide powder method using FTIR spectrophotometer (Prestege-21, Shimadzu, Japan) for understanding the constituent capping and reducing agents of silver nanoparticles. Also, elemental composition of the synthesized silver nanoparticles was analyzed with an energy dispersive X-ray spectroscope instrument (TM-10000 with EDX). To identify the structural phase present in the AgNP, XRD was performed by XRD instrument (Shimadzu, Maxima-X-7000) operating at $40 \mathrm{kV}$ with a current of $30 \mathrm{~mA}$ and Co-Ka radiation. And crystalline size was determined by Scherrer equation. In order to understand the size distribution and surface charge, the zeta potential (ZetaCompact, CAD Instruments, France) and Photon Cross-correlation Spectroscopy (PCCS) (NANOPHOX $1 \mathrm{~nm}$ to 10,000 nm, Sympatec GmbH, Germany) methods was used for dispersed nanoparticles of silver.

Atomic force microscope (AFM) measurement. The size of the synthesized AgNP was analyzed with Atomic Force Spectroscopy (SPA 300, Seiko Inc., Japan). First, the siliconized glass cover slides selected for the AFM measurement were immersed in ultra-pure water and sonicated for $10 \mathrm{~min}$ with ultra sonicator, afterwards the siliconized glass cover slides were rinsed with ethanol solution and air-dried in laminar box at RT, then the samples for AFM analysis were prepared by drying the AgNP suspension on prepared siliconized glass cover slide at RT. Finally, Atomic Force Microscope was used to analyze the morphology and size of the samples via golden silicon probe (GSG11) with tip curvature radius of $10 \mathrm{~nm}$.

Determination of anti-bacterial activity using well diffusion method. The agar well diffusion method was used to study the antibacterial activity of the synthesized silver nanoparticle. Broth medium was used to subculture bacteria and was incubated at $37^{\circ} \mathrm{C}$ for $24 \mathrm{~h}$, afterwards, overnight cultures were taken and spread on the agar plates to cultivate a uniform microbial growth plate. The bacterial strains were gram-negative Escherichia coli and gram-positive Micrococcus luteus. And silver nitrate, plant extract, antibiotics (Penicillin G against Micrococcus luteus and Chloramphenicol against Escherichia coli) were chosen as the control group for 
the study of antibacterial activity. Finally, the petri dishes were incubated for $24 \mathrm{~h}$ at $37^{\circ} \mathrm{C}$. In order to evaluate the antibacterial activity of the synthesized silver nanoparticle, the diameter of the inhibition zone was measured and compared with the control groups.

Cell culture. The cell line HepG2 was cultured in Dulbecco's Modified Eagle Medium (DMEM) medium supplemented with $10 \%$ Fetal Bovine Serum (FBS), $1 \%$ penicillin, $1 \%$ streptomycin and maintained in standard condition with $5 \% \mathrm{CO}_{2}$ humidified incubator at $37^{\circ} \mathrm{C}$ temperature. Prior treatment, the cells were seeded in 96-well tissue culture plates with a seeding density of $2 \times 10^{4}$ cells and incubated overnight. The cell line HepG2 were sub-cultured at $70-80 \%$ confluence and used for further study.

Crystal violet assay. The crystal violet assay was performed to determine the cell viability according to the method described by Feoktistova et al. Crystal violet is a dye which binds to DNA and protein of cells and used for studying viable cells that are adhered to the cell culture plates. In order to study the cytotoxicity of the synthesized AgNP-W, AgNP-F and AgNP-S, the nanoparticles were first filtered with $0.45 \mu \mathrm{m}$ filter. Different concentration of AgNP-W, AgNP-F and AgNP-S suspension (3-17 $\mu \mathrm{g} / \mathrm{ml}$ ) were added to triplicate well and incubated for $24 \mathrm{~h}$. After treatment the medium was removed and the cells were washed twice with PBS, followed by staining with $50 \mu \mathrm{l}$ of $0.5 \%$ crystal violet dye for $20 \mathrm{~min}$ at room temperature. Thereafter, crystal violet dye was removed and the wells were washed in a stream of tap water and left to air-dry for $3 \mathrm{~h}$ at room temperature. The crystal violet dye was dissolved with the addition of methanol to each well and the absorbance was measured at $570 \mathrm{~nm}$ with ELISA reader.

Statistical analysis. All experiments were performed at least three times, independently and data were analyzed by a Student's t-test, and a value of $\mathrm{p}<0.05$ was considered significant.

Received: 19 May 2021; Accepted: 11 October 2021

Published online: 26 October 2021

\section{References}

1. Rafique, M. S., Sadaf, I., Rafique, M. S. \& Tahir, M. B. A review on green synthesis of silver nanoparticles and their applications. Artif. Cells Nanomed. Biotechnol. 45(7), 1272-1291. https://doi.org/10.1080/21691401.2016.1241792 (2017).

2. Abdelghany, T. M. et al. Recent advances in green synthesis of silver nanoparticles and their applications: About future directions. A review. Bionanoscience. 8(1), 5-16. https://doi.org/10.1007/s12668-017-0413-3 (2018).

3. Shah, M., Fawcett, D., Sharma, S., Tripathy, S. K. \& Poinern, G. E. J. Green synthesis of metallic nanoparticles via biological entities. Materials (Basel). 8(11), 7278-7308. https://doi.org/10.3390/ma8115377 (2015).

4. Jyoti, K., Baunthiyal, M. \& Singh, A. Characterization of silver nanoparticles synthesized using Urtica dioica Linn. leaves and their synergistic effects with antibiotics. J. Radiat. Res. Appl. Sci. 9(3), 217-227. https://doi.org/10.1016/j.jrras.2015.10.002 (2016).

5. Iravani, S., Korbekandi, H., Mirmohammadi, S. V. \& Zolfaghari, B. Synthesis of silver nanoparticles: Chemical, physical and biological methods. Res. Pharm. Sci. 9(6), 385-406 (2014).

6. Khandel, P., Shahi, S. K., Soni, D. K., Yadaw, R. K. \& Kanwar, L. Alpinia calcarata: Potential source for the fabrication of bioactive silver nanoparticles. Nano Converg. https://doi.org/10.1186/s40580-018-0167-9 (2018).

7. Mounika, K. C., Venakatesh, J., Manogna, K. \& Paul, A. D. Biosynthesis and characterization of silver nanoparticles from tuber extract of Cyperus rotundus and study of its antibacterial activity. Res. J. Pharm. Biol. Chem. Sci. 8(5), 378-387 (2017).

8. Bala, A. \& Rani, G. A review on phytosynthesis, affecting factors and characterization techniques of silver nanoparticles designed by green approach. Int. Nano Lett. 10(3), 159-176. https://doi.org/10.1007/s40089-020-00309-7 (2020).

9. Rajendran, R. et al. Green synthesis, characterization, antimicrobial and cytotoxic effects of silver nanoparticles using Origanum heracleoticum L. leaf extract. Int. J. Pharm. Pharm. Sci. 7(4), 288-293 (2015).

10. Lee, S. H. \& Jun, B. H. Silver nanoparticles: Synthesis and application for nanomedicine. Int. J. Mol. Sci. https://doi.org/10.3390/ ijms20040865 (2019)

11. Siddiqi, K. S., Husen, A. \& Rao, R. A. K. A review on biosynthesis of silver nanoparticles and their biocidal properties. J. Nanobiotechnol. https://doi.org/10.1186/s12951-018-0334-5 (2018).

12. Mittal, A. K. et al. Bio-synthesis of silver nanoparticles using Potentilla fulgens Wall. ex Hook. and its therapeutic evaluation as anticancer and antimicrobial agent. Mater. Sci. Eng. C Mater. Biol. Appl. 53, 120-127. https://doi.org/10.1016/j.msec.2015.04.038 (2015).

13. Tashi, T., Vishal Gupta, N. \& Mbuya, V. B. Silver nanoparticles: Synthesis, mechanism of antimicrobial action, characterization, medical applications, and toxicity effects. J. Chem. Pharm. Res. 8(2), 526-537 (2016).

14. Xu, D. P. et al. Natural antioxidants in foods and medicinal plants: Extraction, assessment and resources. Int. J. Mol. Sci. 18(1), 20-31. https://doi.org/10.3390/ijms18010096 (2017).

15. Review, M. A review on green silver nanoparticles based on plants: Synthesis, potential applications and eco-friendly approach. Int. Food Res. J. 23(2), 446-463 (2016).

16. Yaqoob, A. A., Umar, K. \& Ibrahim, M. N. M. Silver nanoparticles: Various methods of synthesis, size affecting factors and their potential applications-a review. Appl. Nanosci. 10(5), 1369-1378. https://doi.org/10.1007/s13204-020-01318-w (2020).

17. Vijayan, R., Joseph, S. \& Mathew, B. Green synthesis, characterization and applications of noble metal nanoparticles using $M y x o-$ pyrum serratulum a. W. Hill leaf extract. Bionanoscience. 8(1), 105-117. https://doi.org/10.1007/s12668-017-0433-z (2018).

18. Natsuki, J. A review of silver nanoparticles: Synthesis methods, properties and applications. Int. J. Mater. Sci. Appl. 4(5), 325. https:// doi.org/10.11648/j.ijmsa.20150405.17 (2015).

19. Saha, J., Begum, A., Mukherjee, A. \& Kumar, S. A novel green synthesis of silver nanoparticles and their catalytic action in reduction of Methylene Blue dye. Sustain. Environ. Res. 27(5), 245-250. https://doi.org/10.1016/j.serj.2017.04.003 (2017).

20. Chaudhuri, S. K., Chandela, S. \& Malodia, L. Plant mediated green synthesis of silver nanoparticles using Tecomella undulata leaf extract and their characterization. Nano Biomed. Eng. 8(1), 1-8. https://doi.org/10.5101/nbe.v8i1.p1-8 (2016).

21. Ali, M. et al. Green synthesis and characterization of silver nanoparticles using Artemisia absinthium aqueous extract-A comprehensive study. Mater. Sci. Eng. C 58, 359-365. https://doi.org/10.1016/j.msec.2015.08.045 (2016).

22. Gomathi, M., Rajkumar, P. V., Prakasam, A. \& Ravichandran, K. Green synthesis of silver nanoparticles using Datura stramonium leaf extract and assessment of their antibacterial activity. Resour. Technol. 3(3), 280-284. https://doi.org/10.1016/j.reffit.2016.12. 005 (2017). 
23. Raja, S., Ramesh, V. \& Thivaharan, V. Green biosynthesis of silver nanoparticles using Calliandra haematocephala leaf extract, their antibacterial activity and hydrogen peroxide sensing capability. Arab. J. Chem. 10(2), 253-261. https://doi.org/10.1016/j.arabjc. 2015.06.023 (2017).

24. Banala, R. R., Nagati, V. B. \& Karnati, P. R. Green synthesis and characterization of Carica papaya leaf extract coated silver nanoparticles through X-ray diffraction, electron microscopy and evaluation of bactericidal properties. Saudi J. Biol. Sci. 22(5), 637-644. https://doi.org/10.1016/j.sjbs.2015.01.007 (2015).

25. Davaakhuu, G., Sukhdolgor, J. \& Gereltu, B. Lipid lowering effect of ethanolic extract of Carduus crispus l. On hypercholesterolemic rats. Mong J. Biol. Sci. 8(2), 49-51. https://doi.org/10.22353/mjbs.2010.08.14 (2010).

26. Awobajo, F. O., Adegoke, O. \& Odugbemi, T. O. Phytochemical and antimicrobial screening of Hybanthus enneaspermus and paquetina nigricense. Rec. Res. Sci. Technol. 1(4), 159-160 (2009).

27. Baumberger, J., Brantner, A., Kunert, O. \& Bucar, F. Phytochemical and biological investigations on Carduus crispus L.. Planta Medica https://doi.org/10.1055/s-0030-1264365 (2010).

28. Kambale, E. K. et al. Green synthesis of antimicrobial silver nanoparticles using aqueous leaf extracts from three Congolese plant species (Brillantaisia patula, Crossopteryx febrifuga and Senna siamea). Heliyon 6(8), e04493. https://doi.org/10.1016/j.heliyon. 2020.e04493 (2020).

29. Liao, C., Li, Y. \& Tjong, S. C. Bactericidal and cytotoxic properties of silver nanoparticles. Int J Mol Sci. https://doi.org/10.3390/ ijms20020449 (2019).

30. Arokiyaraj, S. et al. Green synthesis of silver nanoparticles using Rheum palmatum root extract and their antibacterial activity against Staphylococcus aureus and Pseudomonas aeruginosa. Artif. Cells Nanomed. Biotechnol. 45(2), 372-379. https://doi.org/10. 3109/21691401.2016.1160403 (2017).

31. Padalia, H., Moteriya, P. \& Chanda, S. Green synthesis of silver nanoparticles from marigold flower and its synergistic antimicrobial potential. Arab. J. Chem. 8(5), 732-741. https://doi.org/10.1016/j.arabjc.2014.11.015 (2015).

32. Khan, M. et al. Plant extracts as green reductants for the synthesis of silver nanoparticles: Lessons from chemical synthesis. Dalt Trans. 47(35), 11988-12010. https://doi.org/10.1039/C8DT01152D (2018).

33. Mata, R., Nakkala, J. R. \& Sadras, S. R. Biogenic silver nanoparticles from Abutilon indicum: Their antioxidant, antibacterial and cytotoxic effects in-vitro. Colloids Surf. B Biointerfaces. 128, 276-286. https://doi.org/10.1016/j.colsurfb.2015.01.052 (2015).

34. Krupa, A. N. D. \& Raghavan, V. Biosynthesis of silver nanoparticles using Aegle marmelos (bael) fruit extract and its application to prevent adhesion of bacteria: A strategy to control microfouling. Bioinorg. Chem. Appl. https://doi.org/10.1155/2014/949538 (2014).

35. Annamalai, P., Balashanmugam, P. \& Kalaichelvan, P. T. Biogenic synthesis silver nanoparticles using peltophorum pterocarpum leaf extracts and its antimicrobial efficacy against selective pathogens. Int. J. Appl. Pharm. 10(6), 112-118. https://doi.org/10.22159/ ijap.2018v10i6.28573 (2018).

36. Mohamed, N. H., Ismail, M. A., Abdel-Mageed, W. M. \& Shoreit, A. A. M. Antimicrobial activity of latex silver nanoparticles using Calotropis procera. Asian Pac J Trop Biomed. 4(11), 876-883. https://doi.org/10.12980/APJTB.4.201414B216 (2014).

37. Bhakya, S., Muthukrishnan, S., Sukumaran, M. \& Muthukumar, M. Biogenic synthesis of silver nanoparticles and their antioxidant and antibacterial activity. Appl. Nanosci. 6(5), 755-766. https://doi.org/10.1007/s13204-015-0473-z (2016).

38. Kumara Swamy, M., Sudipta, K. M., Jayanta, K. \& Balasubramanya, S. The green synthesis, characterization, and evaluation of the biological activities of silver nanoparticles synthesized from Leptadenia reticulata leaf extract. Appl. Nanosci. 5(1), 73-81. https:// doi.org/10.1007/s13204-014-0293-6 (2015).

39. Sharma, P. et al. Green synthesis and characterization of silver nanoparticles by Allium cepa L. to produce silver nano-coated fabric and their antimicrobial evaluation. Appl. Organomet. Chem. 32(3), 1-13. https://doi.org/10.1002/aoc.4146 (2018).

40. Abdel-Aziz, M. S., Shaheen, M. S., El-Nekeety, A. A. \& Abdel-Wahhab, M. A. Antioxidant and antibacterial activity of silver nanoparticles biosynthesized using Chenopodium murale leaf extract. J. Saudi Chem. Soc. 18(4), 356-363. https://doi.org/10.1016/j.jscs. 2013.09.011 (2014).

41. Syafiuddin, A., Salmiati, H. T., Beng Hong Kueh, A. \& Razman, S. M. Novel weed-extracted silver nanoparticles and their antibacterial appraisal against a rare bacterium from river and sewage treatment plan. Nanomaterials https://doi.org/10.3390/nano8 010009 (2014).

42. Sahni, G., Panwar, A. \& Kaur, B. Controlled green synthesis of silver nanoparticles by Allium cepa and Musa acuminata with strong antimicrobial activity. Int. Nano Lett. 5(2), 93-100. https://doi.org/10.1007/s40089-015-0142-y (2015).

43. Kumar, B., Smita, K., Cumbal, L. \& Debut, A. Green synthesis of silver nanoparticles using Andean blackberry fruit extract. Saudi J. Biol. Sci. 24(1), 45-50. https://doi.org/10.1016/j.sjbs.2015.09.006 (2017).

44. Chung, I. M., Park, I., Seung-Hyun, K., Thiruvengadam, M. \& Rajakumar, G. Plant-mediated synthesis of silver nanoparticles: Their characteristic properties and therapeutic applications. Nanoscale Res. Lett. 11(1), 1-14. https://doi.org/10.1186/s11671-0161257-4 (2016).

45. Power, A. C., Betts, A. J. \& Cassidya, J. F. Non aggregated colloidal silver nanoparticles for surface enhanced resonance Raman spectroscopy. Analyst 136, 2794. https://doi.org/10.1039/C1AN15250E (2011).

46. Saion, E., Gharibshahi, E. \& Naghavi, K. Size-controlled and optical properties of monodispersed silver nanoparticles synthesized by the radiolytic reduction method. Int. J. Mol. Sci. 14(4), 7880-7896. https://doi.org/10.1039/C1AN15250E (2013).

47. Jorge de Souza, T. A., Rosa Souza, L. R. \& Franchi, L. P. Silver nanoparticles: An integrated view of green synthesis methods, transformation in the environment, and toxicity. Ecotoxicol. Environ. Saf. 171, 691-700. https://doi.org/10.1016/j.ecoenv.2018. 12.095 (2019).

48. Netala, V. R. et al. Biogenesis of silver nanoparticles using endophytic fungus Pestalotiopsis microspora and evaluation of their antioxidant and anticancer activities. Int. J. Nanomed. 11, 5683-5696. https://doi.org/10.2147/IJN.S112857 (2016).

49. Chauhan, N., Tyagi, A. K., Kumar, P. \& Malik, A. Antibacterial potential of Jatropha curcas synthesized silver nanoparticles against food borne pathogens. Front Microbiol. 7, 1-13. https://doi.org/10.3389/fmicb.2016.01748 (2016).

50. Akinsiku, A. Green synthesis of capped silver nanoparticles and their hybrids: Antimicrobial and optical properties by akinsiku anuoluwa abimbola. Covenant University (2017). http://eprints.covenantuniversity.edu.ng/9513/

51. Firouz, F., Farshad, H., Amir-Ahmad, S., Hamidreza, A. \& Hossein, R. Toxicity effect of silver nanoparticles on mice liver primary cell culture and HepG2 cell line. Iran. J. Pharm. Res. 13(1), 235-242 (2014).

52. Kanti, S., Kannan, B. N. \& Sung, S. H. Environmentally sustainable synthesis of catalytically-active silver nanoparticles and their cytotoxic effect on human keratinocytes. J. Cluster Sci. 28, 1605-1616. https://doi.org/10.1007/s10876-017-1169-1 (2017).

\section{Acknowledgements}

We gratefully acknowledge the assistance from Associate Professor Lkhagvasuren.D Department of Biology, National University of Mongolia and Associate Professor Tegshjargal.Kh Department of Chemical and Biological Engineering. This work was supported by the Science Technology Foundation grant funded by the Mongolian Government. 


\section{Author contributions}

E.U., B.B. and T.M. designed the experiments. E.U., B.B., A.G. and N.S. conducted the experiments. E.U. and B.B. analyzed the data. E.U. and B.B. wrote the manuscript.

\section{Competing interests}

The authors declare no competing interests.

\section{Additional information}

Correspondence and requests for materials should be addressed to E.U. or T.M.-O.

Reprints and permissions information is available at www.nature.com/reprints.

Publisher's note Springer Nature remains neutral with regard to jurisdictional claims in published maps and institutional affiliations.

(c) (i) Open Access This article is licensed under a Creative Commons Attribution 4.0 International License, which permits use, sharing, adaptation, distribution and reproduction in any medium or format, as long as you give appropriate credit to the original author(s) and the source, provide a link to the Creative Commons licence, and indicate if changes were made. The images or other third party material in this article are included in the article's Creative Commons licence, unless indicated otherwise in a credit line to the material. If material is not included in the article's Creative Commons licence and your intended use is not permitted by statutory regulation or exceeds the permitted use, you will need to obtain permission directly from the copyright holder. To view a copy of this licence, visit http://creativecommons.org/licenses/by/4.0/.

(C) The Author(s) 2021 